\title{
Predictive value of mean platelet volume in gold induced thrombocytopenia
}

\author{
P S KLIMIUK, P J L HOLT, R B CLAGUE, E HEROD, AND P A DYER
}

From the Rheumatism Research Centre and Department of Haematology, Manchester Royal Infirmary, Tissue Typing Laboratory, St Mary's Hospital, Manchester; and the Department of Medical Genetics, University of Manchester

SUMMARY In rheumatoid arthritis the mean platelet volume does not alter with the institution of parenteral gold therapy and with long term gold therapy. It appears to have no value in predicting the onset of thrombocytopenia. It may, however, predict a haemorrhagic diathesis once gold induced thrombocytopenia is established.

Key word: chrysotherapy.

Parenteral gold therapy is an established treatment in rheumatoid arthritis. Thrombocytopenia is a recognised complication of this treatment, and in a small number of patients there may be life threatening haemorrhage. ${ }^{12}$ It is an unpredictable event and occurs in $1-3 \%$ of patients treated with gold. ${ }^{3}$ It has been shown that platelet size correlates with platelet function. ${ }^{45}$ The Coulter counter model $\mathrm{S}$ plus is a haematological analyser designed for routine laboratory use and provides a full blood count together with platelet parameters, including the mean platelet volume (MPV). ${ }^{6}$ To determine whether MPV could predict the onset of thrombocytopenia and possible haemorrhage this study examined the effects of gold on the MPV and the changes in MPV during thrombocytopenia.

\section{Patients and methods}

The Rheumatism Research Centre provides a monitoring service for some of the patients starting to receive disease modifying agents. The haematological records of all patients with rheumatoid arthritis receiving parenteral gold therapy were examined after introduction of the Coulter counter model S plus in 1982. Intramuscular chrysotherapy was instituted along standard lines, i.e., $10 \mathrm{mg}$ weekly or $10 \mathrm{mg}$ followed by $50 \mathrm{mg}$ weekly until benefit, then $50 \mathrm{mg}$ at fortnightly or three-weekly intervals. Complete data were obtained on 25 patients who were established on gold therapy for more than one

Accepted for publication 13 June 1986.

Correspondence to Dr P S Klimiuk, Department of Rheumatology, Stopford Building, Oxford Road, Manchester M13 9PT. year. A further 14 patients were studied in whom gold therapy was instituted. Platelet counts and MPV were analysed before starting treatment, at four months, and at one year.

Over a two year period five patients with rheumatoid arthritis receiving gold therapy developed severe thrombocytopenia (platelet count $\left(<20 \times 10^{9}\right)$ 1). Platelet counts and MPV were analysed before institution of parenteral gold therapy, during the thrombocytopenic episode, and after the recovery in the platelet count.

HLA typing was carried out by the Tissue Typing Laboratory Department of Medical Genetics by a standard microtoxicity method as previously described. $^{7}$

Platelet antibodies were measured by a modified enzyme linked immunosorbent assay in routine use at the blood transfusion laboratory, Manchester Royal Infirmary. Statistical analysis was carried out with the Kolmogorov-Smirnov goodness of fit test. Two tailed Student $t$ tests were performed for comparison between the different groups.

\section{Results}

The average MPV in 113 healthy volunteers was

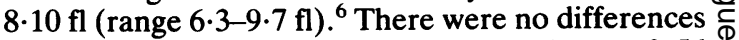
in the MPVs of these patients and those of $56 \stackrel{?}{?}$ patients with rheumatoid arthritis not receiving 0 disease modifying agents $(8.2$ (SD 1.3) fl, range 6.3-9.7 fl). This latter group showed no significant differences in MPV compared with healthy controls. $\mathbb{D}$

In 14 patients with rheumatoid arthritis receiving gold treatment the MPV did not alter at four or at 12 
Table 1 Changes in MPV over 12 months in 14 patients receiving gold therapy

\begin{tabular}{lll}
\hline Pretreatment & $\begin{array}{l}\text { After four months } \\
\text { of gold therapy }\end{array}$ & $\begin{array}{l}\text { After 12 months } \\
\text { of gold therapy }\end{array}$ \\
\hline 8.6 (SD 1.2) & 8.9 (SD 0.9) & 8.6 (SD 0.9)
\end{tabular}

months (Table 1). The clinical characteristics of the group with gold induced thrombocytopenia are shown in Table 2. For this thrombocytopenic group of patients the changes in the MPV are shown in Table 3. There was no significant difference between the pretreatment values of MPV and those of patients receiving gold therapy. One patient (No 5) developed a haemorrhagic diathesis with bleeding from multiple sites and required platelet transfusion. The MPV in this patient was significantly lower during the thrombocytopenic episode (5.6 (SD 0.1) fl) compared with the other thrombocytopenic patients without haemorrhage $(11.2 \quad(3.5) \mathrm{fl}$; $\mathrm{p}<0.001)$. The relation between the MPV and the platelet count in this patient is shown in Fig. 1. It should be noted that this patient developed a mucocutaneous reaction after institution of gold therapy. Because the oropharynx was involved she was started on prednisolone $20 \mathrm{mg} / \mathrm{day}$. This can be contrasted with patient No 3 who showed no
Table 3 MPV and gold induced thrombocytopenia

\begin{tabular}{lcc}
\hline Patient No & \multicolumn{2}{c}{ Mean platelet volume $(S D)(f l)$} \\
\cline { 2 - 3 } & Pretreatment & During thrombocytopenia \\
\hline Non-haemorrhagic: & & \\
1 & 9.6 & $8.6(0 \cdot 7)$ \\
2 & 9.7 & $10 \cdot 6$ \\
3 & $9 \cdot 1$ & $16.2(2 \cdot 0)$ \\
4 & $10 \cdot 1$ & $9.3(3.5)$ \\
Haemorrhagic: & & \\
5 & 9.6 & $5.6(0.1)$ \\
\hline
\end{tabular}

evidence of haemorrhage but had a comparable degree of thrombocytopenia and an increased MPV (Fig. 2). Sternal marrow aspirations in all our patients showed active megakaryocytosis, but antiplatelet antibodies were not detected in any of our thrombocytopenic patients. All the patients showed a rapid response to high dose oral prednisolone with normal platelet counts within five days. A transient fall in the platelet count was observed when the prednisolone dosage was reduced too quickly in two of the patients. The platelet count recovered rapidly on a temporarily increased dose of prednisolone.

All the five thrombocytopenic patients were HLA-DR3.

Table 2 Clinical characteristics of the group with gold induced thrombocytopenia

\begin{tabular}{|c|c|c|c|c|c|}
\hline \multirow[t]{2}{*}{ Characteristic } & \multicolumn{5}{|l|}{ Patient } \\
\hline & No 1 & No 2 & No 3 & No 4 & No 5 \\
\hline Age (years) & 53 & 56 & 49 & 57 & 37 \\
\hline Sex & $\mathbf{F}$ & $\mathbf{F}$ & $\mathbf{F}$ & $\mathbf{M}$ & $\mathbf{F}$ \\
\hline Disease duration & & & & & 1 \\
\hline (years) & 25 & 11 & 15 & 11 & 10 \\
\hline Previous medications & $\begin{array}{l}\text { Gold } 1957 \\
\text { Chloro* } 1980\end{array}$ & 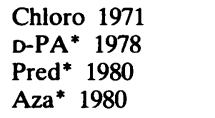 & Chloro 1978 & $\begin{array}{l}\text { Chloro } 1982 \\
\text { D-PA } 1982\end{array}$ & NSAIDs* \\
\hline $\begin{array}{l}\text { Duration of current } \\
\text { gold therapy }\end{array}$ & 4 months & 6 weeks & 22 months & 9 weeks & 3 weeks \\
\hline Total dose of gold (g) & 0.75 & $0 \cdot 30$ & $2 \cdot 2$ & 0.45 & 0.15 \\
\hline SCAT $^{*}$ & $1 / 256$ & $1 / 256$ & $1 / 16$ & $1 / 256$ & $1 / 512$ \\
\hline $\mathrm{ANF}^{*}$ & Negative & Negative & Negative & Negative & Negative \\
\hline Haematuria & Not detected & Not detected & Not detected & Not detected & Frank haematuria \\
\hline Marrow findings & $\begin{array}{l}\text { Plentiful } \\
\text { megakaryocytes }\end{array}$ & $\begin{array}{l}\text { Plentiful } \\
\text { megakaryocytes }\end{array}$ & $\begin{array}{l}\text { Plentiful } \\
\text { megakaryocytes }\end{array}$ & $\begin{array}{l}\text { Plentiful } \\
\text { megakaryocytes }\end{array}$ & $\begin{array}{l}\text { Plentiful } \\
\text { megakaryocytes }\end{array}$ \\
\hline $\begin{array}{l}\text { HLA type } \\
\text { Haemorrhagic diathesis }\end{array}$ & $\begin{array}{l}A_{1.3 .} B_{7.35} D_{2} \cdot 3 . \\
\text { Mild cutaneous } \\
\text { purpura }\end{array}$ & $\begin{array}{l}A_{2 \cdot 3 .} B_{7.27} D_{R_{3 \cdot 6}} \\
\text { Mild cutaneous } \\
\text { purpura }\end{array}$ & $\begin{array}{l}A_{1.3 .} B_{8 \cdot 40 .} D_{R_{3}} \\
\text { None }\end{array}$ & $\begin{array}{l}A_{1.3 .} B_{7.8} . D_{2.3 .} \\
\text { None }\end{array}$ & $\begin{array}{l}A_{1.2} \cdot B_{7 \cdot 8 .} D_{3.4} \\
\text { Frank } \\
\text { haemorrhage. } \\
\text { Many sites. }\end{array}$ \\
\hline
\end{tabular}

${ }^{*}$ SCAT $=$ sheep cell agglutination titre; $\mathrm{ANF}=$ antinuclear factor; Chloro=chloroquine; D-PA=D-penicillamine; Aza=Azathioprine; Pred=prednisolone; NSAIDs=non-steroidal anti-inflammatory drugs. 


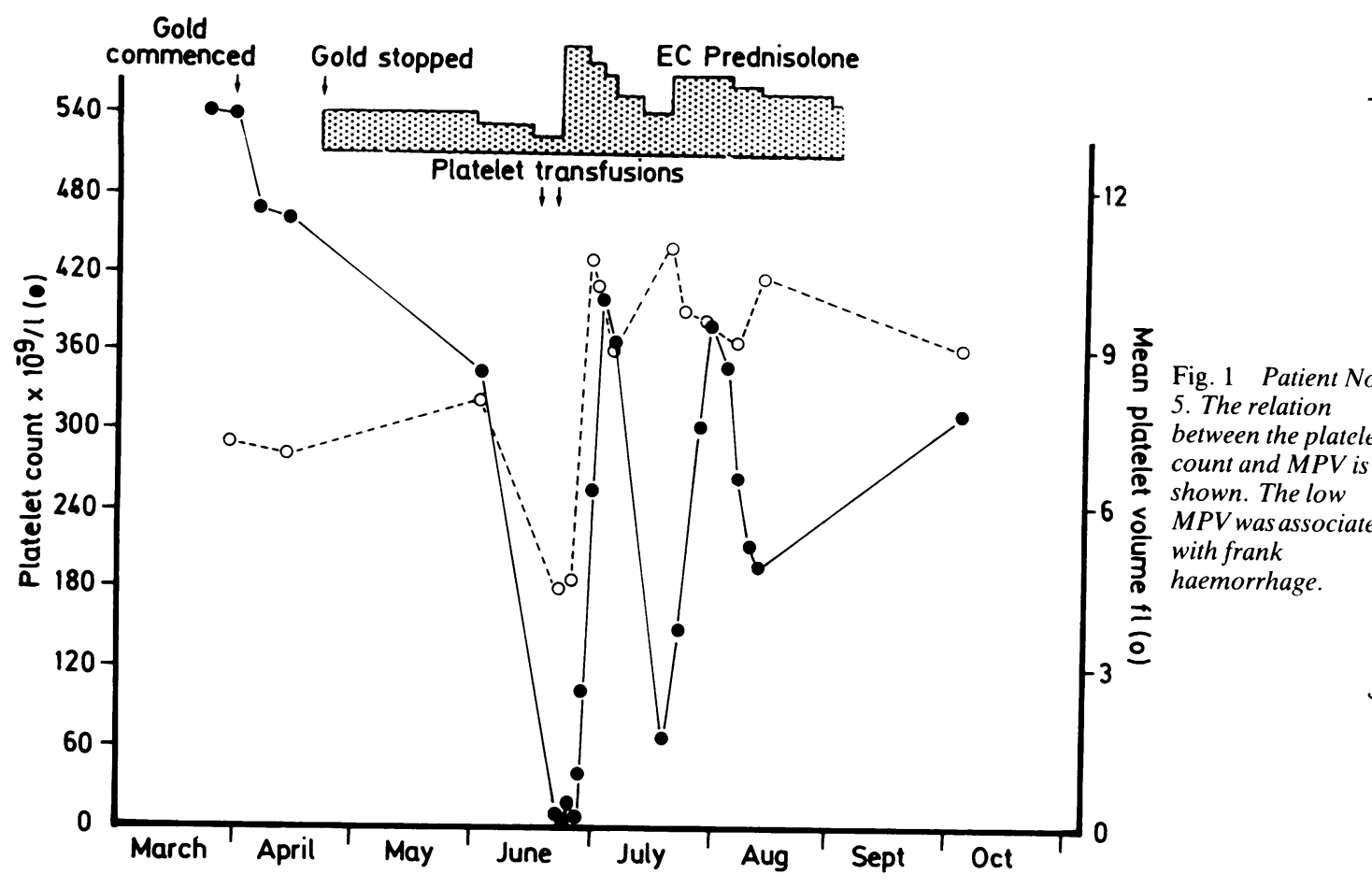

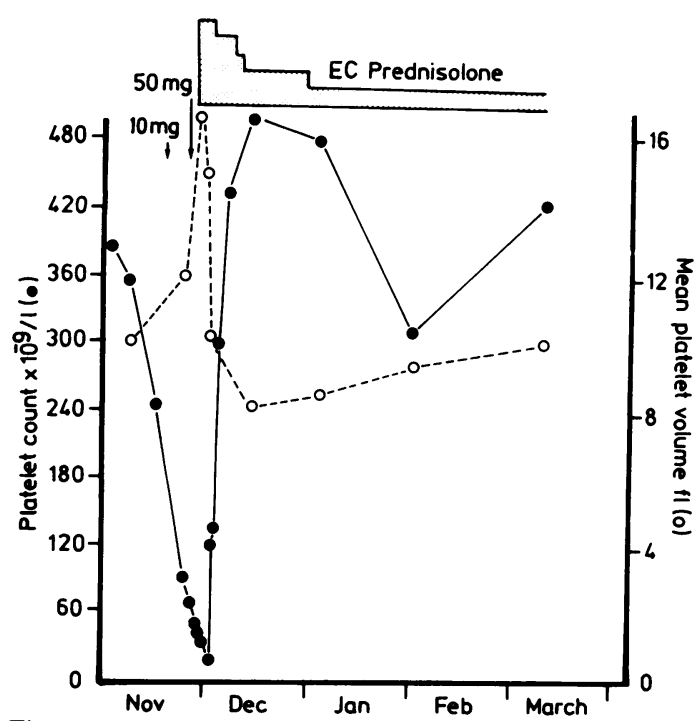

Fig. 2 Patient No 3. The relation between the platelet count and MPV is shown. The MPV rises and there is no haemorrhage.

\section{Discussion}

The pathogenesis of gold associated thrombocy- topenia is not known. Several studies have shown $\overrightarrow{\overrightarrow{0}}$ the unpredictable nature of the thrombocyto- $\frac{3}{3}$ penia. ${ }^{8-10}$ Direct marrow toxicity cannot be excluded, however the presence of adequate or increasedo megakaryocytes suggests a peripheral platelet destruction, but the precise mechanisms have not been $\overline{0}$ identified. ${ }^{11}$ Some cases of gold associated thrombocytopenia have an abrupt onset after the institution of parenteral gold therapy. This might suggest a $\subseteq$ hypersensitivity reaction, but the evidence is con- $₹$ flicting. ${ }^{8}$ Active thrombocytosis, shortened platelet 음 survival, platelet phagocytosis by splenic macro- $\rightarrow$ phages, and response to corticosteroid therapy을. suggest the involvement of immune mechanisms. "N This is further supported by the association of the thrombocytopenia and HLA-DR3. ${ }^{9} 1012$

In severe thrombocytopenia not all patients develop a haemorrhagic diathesis. ${ }^{13}{ }^{14}$ This is further supported by the clinical observations that largeco platelets are haemostatically superior to small plate- $\mathbb{\mathscr { D }}$ lets. ${ }^{15}$ It has also been shown that larger platelets $\stackrel{\oplus}{?}$ are metabolically more active than small platelets. ${ }^{4}$ In 0 vitro adhesion and aggregation studies indicate that large platelets are functionally more active. ${ }^{5}$

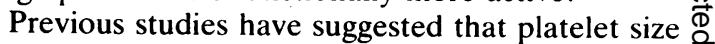
is a major determinant in the haemostatic potential of a thrombocytopenic patient. ${ }^{45}$ The Coulter 
counter model $\mathrm{S}$ plus haematological analyser has greatly facilitated the measurement of platelet size, expressing this parameter as the mean platelet volume. Moreover, the reproducibility and reliability have been validated. ${ }^{6}$

The patterns of thrombocytopenia in our small group of patients are compatible with previous observations. $^{8-10}$ In particular our thrombocytopenic patients would fall into the group with an early precipitous thrombocytopenia, as described by Madhok and his colleagues. ${ }^{10}$ One of our patients was atypical in that the thrombocytopenia was precipitous, but she had been receiving gold therapy for 22 months. We also showed that all our patients with this form of thrombocytopenia were HLADR3. It would therefore appear, as a result of our observations and those of others, ${ }^{10}$ that HLA-DR3 is a very good marker for this type of toxicity.

The relation between MPV and haemorrhage associated with thrombocytopenia was considered by Eldor et al. ${ }^{16}$ They studied a large group of thrombocytopenic patients with a variety of underlying conditions, mostly haematological malignancies. Their data clearly indicated, and were validated statistically, that MPV predicted haemorrhagic diathesis more accurately than the platelet count in severe thrombocytopenia. A MPV of $6.4 \mathrm{fl}$ or less suggested a haemorrhagic diathesis. Our data are in keeping with these findings. Furthermore, both studies employed similar methods of MPV measurement.

The narrow findings in our thrombocytopenic patients would suggest a peripheral destruction of platelets. Antiplatelet antibodies as measured by a modified enzyme linked immunosorbent assay were not detected, however, in our group of patients. Several workers have shown that platelet size increases in conditions associated with active thrombopoiesis. ${ }^{17} 18$ As active megakaryocytosis was observed in all our patients the marrow responses would appear to be appropriate to the thrombocytopenia. It is therefore interesting that patient No 5 who had a very low MPV, although showing a megakaryocyte response, appeared not to produce large platelets This is difficult to explain, but it could be speculated that the gold toxicity is acting at a different site in this case.

High dose oral prednisolone $(60 \mathrm{mg} /$ day $)$, instituted promptly, appears to be an effective form of therapy. One of our patients was already receiving prednisolone $(20 \mathrm{mg} / \mathrm{day})$ when thrombocytopenia developed. This would support the need for high doses initially. Our data suggest that the reduction in prednisolone dosage should be gradual. In two of our patients the thrombocytopenia recurred when the steroid dose was reduced too quickly. The thrombocytopenia, however, was transient and responded quickly to a temporary increase in dosage of prednisolone.

Although this is a small series of patients, it should be noted that severe gold associated thrombocytopenia is a relatively rare event. These preliminary results indicate, however, that the MPV neither changes with parenteral gold therapy nor predicts the onset of the thrombocytopenia. Once thrombocytopenia is established a falling MPV may be a useful indicator of haemorrhage. Monitoring the MPV may have predictive value in the rational use of prophylactic platelet transfusion.

We are indebted to Mrs D Ward for typing this manuscript. We would also like to thank Miss L Hunt for the computation and statistical analysis and the medical illustration department, Hope Hospital, for the illustrations and graphic work.

\section{References}

1 Hartfall S J, Garland H G, Goldie W. Gold treatment of arthritis: a review of 900 cases. Lancet 1937; ii: 784-8, 838-42.

2 Liyanage S P. Gold therapy in 1975. Br Med J 1975; ii: 156-7.

3 Gerber R C, Paulus H E. Gold therapy. Clin Rheum Dis 1975; 1: $307-18$.

4 Karpatkin S. Heterogeneity of human platelets. VI. Correlation of platelet function with platelet volume. Blood 1978; 51: 307-16.

5 Mannucci P M, Sharp M V. Platelet volume and shape in relation to aggregation and adhesion. Br J Haematol 1967; 13: 604-17.

6 Rowan R M, Fraser C, Gray J H, McDonald G A. The Coulter counter model S Plus-the shape of things to come. Clin Lab Haematol 1979; 1: $29-40$.

7 Klimiuk P S, Clague R B, Grennan D M, et al. Autoimmunity to native type II collagen-a distinct genetic subset of RA. J Rheumatol 1985; 12: 865-70.

8 Kay A G L. Myelotoxicity of gold. Br Med J 1976; i: 1268-8.

9 Coblyn J S, Weinblatt M, Holdsworth D, Glass D. Goldinduced thrombocytopenia: a clinical and immunogenetic study of twenty-three patients, Ann Intern Med 1981; 95: 178-81.

10 Madhok R, Pullar T, Capell HA, Dawood F, Sturrock R D, Dick H M. Chrysotherapy and thrombocytopenia. Ann Rheum Dis 1985; 44: 589-91.

11 Levin H A, McMillan R, Tavanoli N, et al. Thrombocytopenia associated with gold therapy: observations on the mechanisms of platelet destruction. JAMA 1975; 59: 274-80.

12 Bardin T, Dryll A, Debeyre N, et al. HLA system and side effects of gold salts and D-penicillamine treatment of rheumatoid arthritis. Ann Rheum Dis 1982; 41: 599-601.

13 Karpatkin S, Gang S K. The megathrombocyte as an index of platelet production. Br J Haematol 1974; 26: 207-11.

14 Hirsh J. Platelet age; its relationship to platelet size, function and metabolism. Br J Haematol 1972; 23: 209-14.

15 Harker L A, Slichter S J. The bleeding time as a screening test for evaluation of platelet function. N Engl J Med 1972; 287: 155-9.

16 Eldor A, Avitzour M, Or R, Hanna R, Penchas S. Prediction of haemorrhagic diathesis in thrombocytopenia by mean platelet volume. Br Med J 1982; 285: 397-400.

17 Garg S K, Amorosi E L, Karpatkin S. Use of the megathrombocyte as an index of megakaryocyte number. $N$ Engl J Med 1971; 284: 11-7.

18 Minter F M, Ingram M. Platelet volume: density relationships in normal and acutely bled dogs. Br J Haematol 1971; 20: 55-68. 